\title{
Effect of Fibers on the Bond Behavior of Deformed Steel Bar Embedded in Recycled Aggregate Concrete
}

\author{
Rashid Hameed ${ }^{1 \mathrm{a}}$, Usman Akmal ${ }^{1 \mathrm{~b}}$, Qasim S. Khan ${ }^{1 \mathrm{c}}$, Muhammad Ahsan Cheema ${ }^{1 \mathrm{~d}}$, \\ Muhammad Rizwan Riaz ${ }^{1 \mathrm{e}}$
}

RECEIVED ON 14.02.2019, ACCEPTED ON 03.05.2019

\begin{abstract}
A large volume of concrete debris is being produced in many countries on the globe due to the demolition of old concrete structures and testing of concrete specimens in laboratories. One of the ways to reuse concrete debris is to produce Recycled Aggregates (RA) and use them in new concrete. In recent years, Recycled Aggregates Concrete (RAC) has experienced increasing demand in various non-structural and structural applications. In reinforced concrete structures, one of the sources of brittle failure is sudden loss of bond between reinforcing bars and concrete in anchorage zones. Therefore, for the structural application of any new kind of concrete such as fiber reinforced RAC, knowledge of bond characteristics of reinforcing bars embedded in concrete becomes essential for determining the overall structural response under different modes of loading. In this regard, this study experimentally investigated the effect of fibers on the bond stress-slip behavior of deformed steel re-bar embedded in RAC. Concrete mixes having 0,50 and $100 \%$ RAs were prepared with and without the addition of fibers. Two types of fibers were investigated in mono form: hooked-ends steel and polypropylene fibers. The dosage of steel and polypropylene fibers was kept 40 and $4.4 \mathrm{~kg} / \mathrm{m}^{3}$, respectively. Axial compression and standard pull-out tests were performed. Test specimens for pull-out test were prepared using deformed steel re-bars of $19 \mathrm{~mm}(\# 6)$ diameter. The results of strength tests confirmed that the compressive strength of concrete is decreased by replacing Natural Aggregates (NA) with RAs. For bond behavior of steel re-bar, the results of this study showed that replacement of 50\% NA with RAs did not affect the bond response of steel bar, however, $100 \%$ replacement of NA with RAs showed detrimental effect on bond stress slip behavior. The results further showed that the addition of both types of fibers made it possible to recover the loss in compressive strength, bond strengths and bond toughness occurred because of replacing NA with RAs. In case of RA concrete mixes containing hooked-ends steel fibers, strength values were found even greater than the strength values of Natural Aggregates Concrete (NAC). From the results of this study, it was found that it is possible to design a structural concrete mix using $100 \%$ RAs and steel fibers at relatively low dosage of $40 \mathrm{~kg} / \mathrm{m}^{3}$.
\end{abstract}

Keywords: Concrete, Recycled Aggregates, Fibers, Steel Re-Bar, Pull-Out Behavior.

\section{INTRODUCTION}

oncrete is one of the most used construction materials in the world. The production of concrete constituents such as cement and coarse aggregates has negative impact on our environment as a result of increasing $\mathrm{CO}_{2}$ emission and depleting reserves of natural resources. Research studies have been carried out all over the world in recent years to recycle the used materials and to

\footnotetext{
${ }^{1}$ Department of Civil Engineering, University of Engineering and Technology, Lahore, Pakistan. Email: ${ }^{\mathrm{a}}$ rashidmughal@ uet.edu.pk (Corresponding Author), ${ }^{\mathrm{b}}$ usman.akmal@uet.edu.pk, ${ }^{\mathrm{c}}$ qasimkhan @ uet.edu.pk,

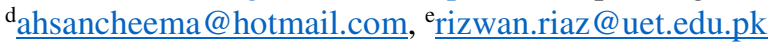

This is an open access article published by Mehran University of Engineering and Technology, Jamshoro under CC BY 4.0 International License.
} 
develop new technologies in order to reduce the negative impact of concrete making on our environment and this has led to the adoption of modern construction techniques and materials. Now-a-days the existing concrete structures are being replaced with more efficiently designed structures due to ever increasing need of space and aesthetics.

A large volume of concrete debris is being produced due to the demolition of concrete structures whose design life has been expired or concrete structures which have been damaged by natural calamities such as earthquakes, high intensity winds and floods. Moreover, the testing of concrete specimens in testing laboratories is also a source of concrete debris. One of the ways being employed these days is to use C\&D (Construction and Demolition) waste in new concrete as RA. The use of RA in concrete was initiated in 1970's to preserve natural resources and reduce the impact on environment. Recently, the RAC has experienced increasing demand in various nonstructural and structural applications [1].

ACI 555R-01 [2] reports that concrete mixes prepared with RA exhibit 5-24\% lower compressive strength than concrete mixes prepared with NA. This is attributed to the fact that RA absorb more water than NA and hence, reduce the water for cement paste hydration resulting in lower compressive strength. Higher reduction in compressive strengths is reported for concrete mixes prepared with recycled fine aggregates. Matias et al. [3] reported that cement paste adhered to the surface of RA resulted in more porous and lighter RAC mix than NAC mix. The adhered cement paste also increased the water absorption of RAC and hence reduced the particle density. Padmini et al. [4] reported that RAC mixes prepared using high strength and small sized coarse RA absorbed more water than RAC mixes prepared using low strength and large sized coarse RA. To achieve the desired workability, the RAC mixes prepared using higher strengths and smaller sized coarse aggregates required higher water to cement ratio in concrete mix than RAC prepared with lower strengths and larger sized coarse aggregates. Xiao et al. [5] investigated 0, 30, 50, 70 and $100 \%$ replacement levels of NA with RA. The compressive strengths of RAC mixes were reported to reduce with increasing replacement levels of NA with
RA. Moreover, the peak strain and total strain in compression were also reported to decrease with increasing replacement levels of NA with RA. Furthermore, stress-strain curves of NAC and RAC were found to be similar. Xiao et. al. [1] compiled a comprehensive database of research studies on RAC from year 1996-2011 and reported that RACs can satisfy the requirement of mechanical strength and therefore, can be used as construction material.

It is a well-established fact that the addition of short discrete fibers of various types in plain concrete has positive impact on its mechanical properties with the exception of compressive strength, however, fibers certainly play positive role in post peak region of compressive stress strain behavior of concrete. The fibers effectively arrest the crack propagation within concrete matrix and significantly improve the post cracking response of concrete [6-9]. Comprehensive review of the literature showed that in the recent years research studies [10-18] have been done to investigate the effects of addition of fibers on the mechanical properties of RAC. Findings of these studies revealed that the detrimental effect of replacing NA with RA on the mechanical properties of concrete may be reduced by the addition of fibers, particularly in the post peak regions.

In Reinforced Concrete (RC) structures, one of the sources of brittle failure is sudden loss of bond between reinforcing bars and concrete in anchorage zones which has been the major cause of local damages and even collapse of concrete structures. In RC elements subjected to inelastic loadings, degradation in the strength and stiffness is linked with slippage of flexural reinforcement. For the structural application of RAC, knowledge of bond characteristics of reinforcing bars embedded in RAC with and without fibers becomes essential for determining the overall structural response under different modes of loading. Xiao et al. [19] reported pull out test results of $10 \mathrm{~mm}$ diameter plain and deformed steel bars embedded in RAC. It was noted that bond between plain steel bar and RAC was function of contents of RAC whereas bond between deformed steel bar and RAC was independent of contents of RAC. Prince et. al. [20] investigated pull out test results of various diameters of deformed steel 
bars $(12,16,20$ and $25 \mathrm{~mm})$ embedded in RAC. The study reported that pull out behavior was a function of bar diameter and bond stress was decreased with increasing diameter of steel bar. Moreover, percentage replacement of NA with RA exhibited minor effect on the bond strength. Kim et al. [21] investigated the bond stress-slip behavior of $16 \mathrm{~mm}$ diameter deformed bar embedded in RAC with varying percentage (0, 30, 60 and $100 \%$ ) replacements of NA with RA. The study reported that no noticeable difference in bond behavior characteristics between NAC and RAC pull-out specimens was evident in the pre-peak and post-peak stages. Xiao and Falkner [22] reported that the RAC pull-out specimens exhibited lower peak bond stress than NAC pull-out specimens.

Previous research studies have shown that bond between reinforcing bars and concrete can be enhanced by replacing the normal concrete with FiberReinforced Concrete (FRC). The bond is improved due to the fact that fibers arrest the splitting cracks developed around the bar during pull out mechanism. Hamad et al. [23] investigated the effect of fiber reinforcement on bond strength of tension lap splices in high-strength concrete and reported that steel fiber reinforcement up to $2 \%$ by volume fraction can increase the bond strength up to $55 \%$. Harajli and Mabsout [24] studied the bond strength of steel reinforcing bars in plain and FRC and reported that addition of fiber reinforcement in plain concrete significantly improves bond strength and ductility. Bilal et al. [25] experimentally investigated the effect of steel fibers on bond strength of hooked bars in normal-strength concrete. The study concluded that the addition of steel fibers in the concrete mix resulted in improvement of peak load and ductility. Hameed et al. [26] carried out an experimental study on bond stress slip behavior of steel bar embedded in FRC and concluded that addition of fibers resulted in improved bond stress slip response at all loading stages which include pre-peak, peak load and post peak loading stages.

The main objective of this experimental study is to understand the bond-stress slip behavior of deformed steel re-bars embedded in Fiber-Reinforced Recycled Aggregate Concrete (FRRAC). For this purpose, standard pull-out tests were performed on concrete specimens prepared using RAC with and without steel and polypropylene fibers reinforcement in mono form. RAC mixes were prepared using 50 and $100 \%$ RA. Hooked-end steel fibers and polypropylene fibers were used at constant dosage of $40 \mathrm{k}$ and $4.4 \mathrm{~kg} / \mathrm{m}^{3}$, respectively. Along with pull-out tests, compressive strength tests were also performed on each concrete composition.

\section{EXPERIMENTAL PROGRAM}

\subsection{Concrete Compositions}

The experimental program reported in this study comprised casting of test specimens for compression test and standard pull-out test in four series based on the type of concrete. Keeping in mind the maximum conservation of natural resources of aggregates, concrete with $100 \%$ RA is investigated in this study and, for the purpose of comparison, one commonly investigated contents of RA in concrete (i.e. 50\%) has also been studied. In Series-I, specimens were cast using NAC and RACs having 50 and 100\% RA. All concrete compositions in Series-I were prepared without addition of any type of fibers. In Series-II, same concrete compositions as in Series-I were cast with addition of steel fibers while in Series-III polypropylene fibers were used instead of steel fibers. Table 1 presents all concrete compositions along with their designation which were prepared for this study. For each concrete mix, three cylinders of diameter 150 $\mathrm{mm}$ and height $300 \mathrm{~mm}$ for compression test and three standard pull out test specimens were prepared.

The test specimens were designated according to the replacement level of NA in concrete with RA such as NAC, RAC50 and RAC100 and also with respect to fibers used like Steel Fiber (SF) and Polypropylene Fibers (PF). The symbol NAC represents concrete mix with $100 \%$ NA which was taken as reference concrete in this study. Similarly, RAC50 and RAC100 represent RAC mixes prepared by replacing 50 and $100 \%$ NA with RA, respectively. The concrete mixes in series-II \& III were further represented by SF and PF. For example, designation RAC50-SF represents RAC mix containing 50\% RA and SF. 


\begin{tabular}{|c|c|c|c|c|c|c|c|c|c|}
\hline \multicolumn{10}{|c|}{ Table 1: Concrete Mixes and their Compositions, $\mathrm{kg} / \mathrm{m}^{3}$} \\
\hline \multirow{2}{*}{ Series } & \multirow{2}{*}{ Concrete Mix } & \multirow{2}{*}{ Cement } & \multicolumn{2}{|c|}{ Coarse Aggregates } & \multirow{2}{*}{ Sand } & \multicolumn{2}{|c|}{ Fibers } & \multirow{2}{*}{ SP } & \multirow{2}{*}{ Water } \\
\hline & & & Natural & Recycled & & $\mathrm{SF}$ & $\mathrm{PF}$ & & \\
\hline \multirow{3}{*}{ I } & NAC & \multirow{9}{*}{320} & 1280 & 0 & \multirow{9}{*}{640} & 0 & 0 & 0 & \multirow{9}{*}{176} \\
\hline & RAC50 & & 640 & 640 & & 0 & 0 & 0 & \\
\hline & RAC100 & & 0 & 1280 & & 0 & 0 & 0 & \\
\hline \multirow{3}{*}{ II } & NAC-SF & & 1280 & 0 & & 40 & 0 & 4.4 & \\
\hline & RAC50-SF & & 640 & 640 & & 40 & 0 & 4.4 & \\
\hline & RAC100-SF & & 0 & 1280 & & 40 & 0 & 4.4 & \\
\hline \multirow{3}{*}{ III } & NAC-PF & & 1280 & 0 & & 0 & 4.4 & 4.4 & \\
\hline & RAC50-PF & & 640 & 640 & & 0 & 4.4 & 4.4 & \\
\hline & RAC100-PF & & 0 & 1280 & & 0 & 4.4 & 4.4 & \\
\hline
\end{tabular}

Similarly, RAC100-PF represents RAC mix containing $100 \%$ RA and PF.

\subsection{Material Properties}

The Ordinary Portland Cement (OPC) was used as a binder in all concrete mixes. Locally available crushed stones were used as NA. The RA used in this experimental work were obtained from the waste of a demolished industrial building with a reported compressive strength of $21 \mathrm{MPa}$. Natural and recycled coarse aggregates are shown in Figs. 1-2, and their properties are given in Table 2. Sieve analysis results for NA and RA are given in Table 3 and their gradation curves are shown in Figs. 3-4, respectively. Locally available river sand was used as fine aggregate in all concrete mixes. Properties of fine aggregates are also given in Table 2. Two types of fibers were investigated in this experimental program: Hooked-ends SF and PF as shown in Figs.5-6, respectively. SF with hooked ends having diameter of 0.5 and length $25 \mathrm{~mm}$ were used. The tensile strength of SF was $1200 \mathrm{MPa}$. PF having tensile strength of $35 \mathrm{MPa}$ and specific gravity of 0.90 were used. Deformed reinforcing steel bars of diameter $19 \mathrm{~mm}$ (\#6) having yield and ultimate tensile strength of 447 and $700 \mathrm{MPa}$, respectively were used in preparation of pull-out test specimen.

\subsection{Preparation of Specimens}

To prepare test specimens for compression and pull out tests, the molds were cleaned and oiled prior to casting. The detail of standard specimen for pullout tests is shown in Fig. 7. In all pull-out test specimens, a short length $\mathrm{L}_{b}$ of reinforcing steel bar was embedded in a concrete cylinder of dimeter $150 \mathrm{~mm}$ and length $300 \mathrm{~mm}$. The embedded length $\mathrm{L}_{b}$ was chosen to be $5 d_{b}$, where $d_{b}$ is the bonded bar diameter (19 mm). According to Choi [27], bonded length of $5 d_{b}$ is short enough to result in a fairly uniform bond stress in pull-out but not long enough to reduce the scatter usually observed in test results when a very short bonded length is used.

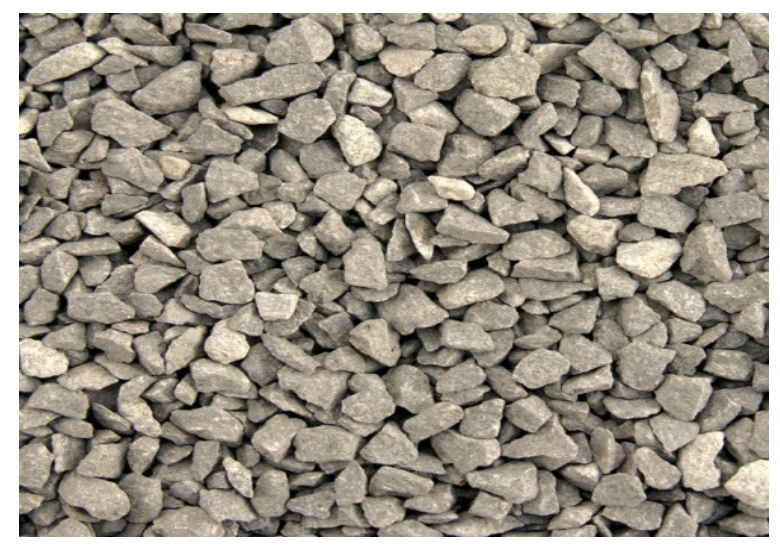

Fig. 1 : Natural Aggregates

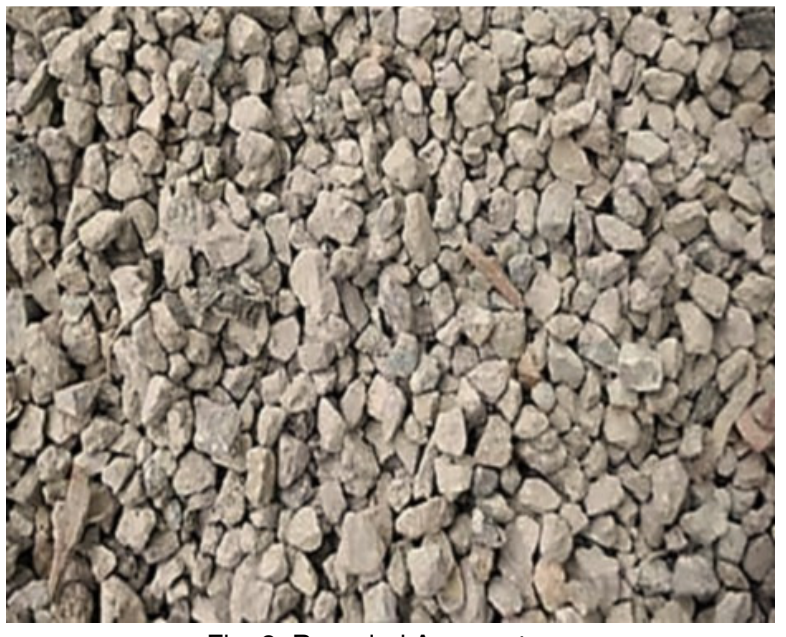

Fig. 2: Recycled Aggregates 


\begin{tabular}{|c|c|c|c|}
\hline \multicolumn{4}{|c|}{ Table 2: Properties of Coarse and Fine Aggregates } \\
\hline Properties & $\begin{array}{c}\text { Natural } \\
\text { Aggregates }\end{array}$ & $\begin{array}{c}\text { Recycled } \\
\text { Aggregates }\end{array}$ & Sand \\
\hline Size (mm) & $4-12$ & $4-12$ & $<4$ \\
\hline $\begin{array}{c}\text { Loose bulk } \\
\text { density } \\
\left(\mathrm{kg} / \mathrm{m}^{3}\right)\end{array}$ & 1690 & 1540 & 1880 \\
\hline $\begin{array}{c}\text { Rodded bulk } \\
\text { density } \\
\left(\mathrm{kg} / \mathrm{m}^{3}\right)\end{array}$ & 1910 & 1750 & 2130 \\
\hline $\begin{array}{c}\text { Water } \\
\text { Absorption } \\
(\%)\end{array}$ & 1.2 & 6.1 & 1.2 \\
\hline $\begin{array}{c}\text { Specific } \\
\text { Gravity }\end{array}$ & 2.59 & 2.36 & 2.69 \\
\hline $\begin{array}{c}\text { Fineness } \\
\text { Modulus }\end{array}$ & 7.53 & 7.56 & 2.20 \\
\hline
\end{tabular}

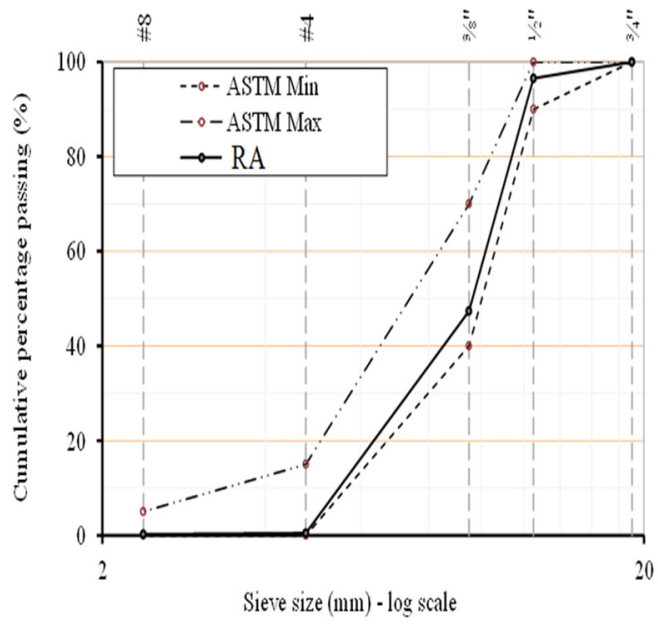

Fig. 4: Gradation Curve of RA

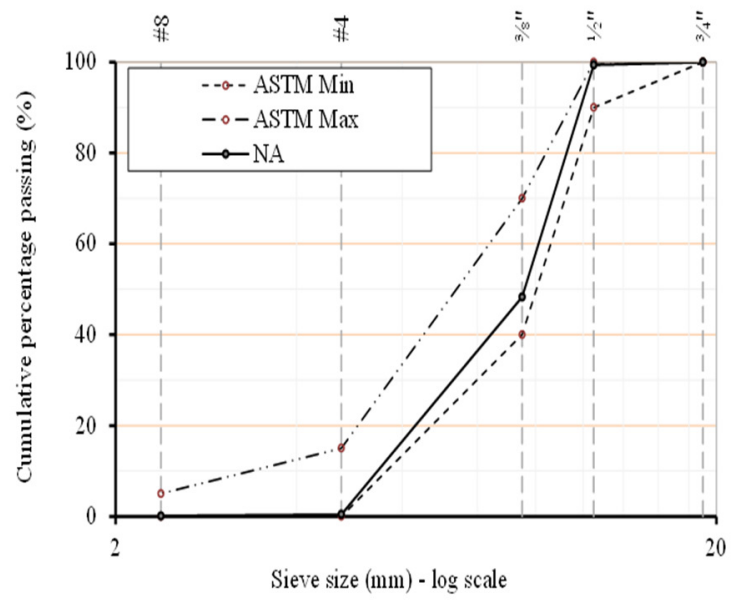

Fig. 3: Gradation Curve of NA

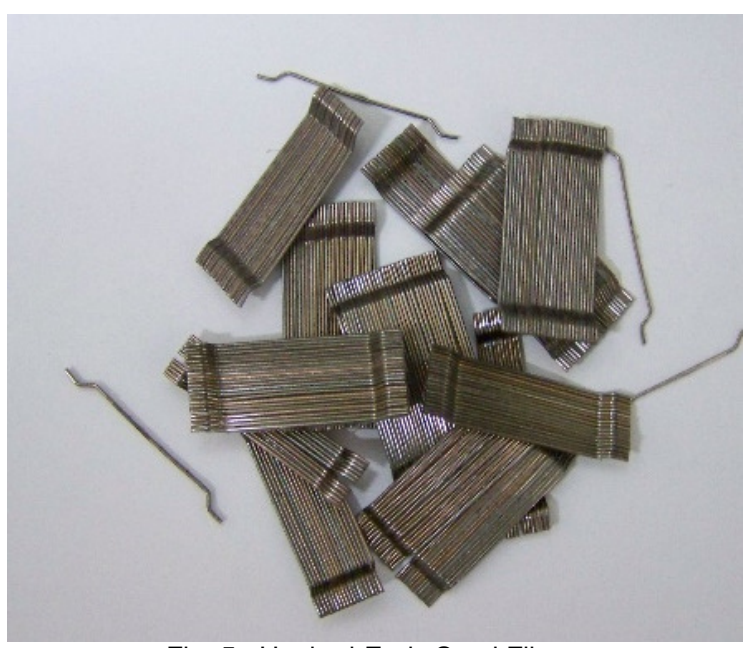

Fig. 5: Hooked-Ends Steel Fibers

\begin{tabular}{|c|c|c|c|c|c|c|c|c|}
\hline \multicolumn{7}{|c|}{ Table 3: Sieve Analysis of NA and RA } \\
\hline $\begin{array}{c}\text { Sieve } \\
\text { Size }\end{array}$ & $\begin{array}{c}\text { Mass } \\
\text { Retained } \\
(\mathrm{g})\end{array}$ & $\begin{array}{c}\text { Retained } \\
(\%)\end{array}$ & $\begin{array}{c}\text { Cumulative } \\
\text { Passing }(\%)\end{array}$ & $\begin{array}{c}\text { Cumulative } \\
\text { Retained } \\
(\%)\end{array}$ & $\begin{array}{c}\text { Mass } \\
\text { Retained } \\
(\mathrm{g})\end{array}$ & $\begin{array}{c}\text { Retained } \\
(\%)\end{array}$ & $\begin{array}{c}\text { Cumulative } \\
\text { Passing }(\%)\end{array}$ & $\begin{array}{c}\text { Cumulative } \\
\text { Retained } \\
(\%)\end{array}$ \\
\hline $\begin{array}{c}19 \mathrm{~mm} \\
(3 / 4 ”)\end{array}$ & 0 & 0 & 100 & 0 & 0 & 0 & 100 & 0 \\
\hline $\begin{array}{c}12.5 \mathrm{~mm} \\
(1 / 2 ")\end{array}$ & 31 & 1 & 99 & 1 & 175 & 4 & 96 & 4 \\
\hline $\begin{array}{c}9.5 \mathrm{~mm} \\
(3 / 8 ”)\end{array}$ & 2572 & 51 & 48 & 52 & 2463 & 49 & 47 & 52 \\
\hline$\# 4$ & 2408 & 48 & 0 & 100 & 2352 & 47 & 0 & 100 \\
\hline$\# 8$ & 16 & 0 & 0 & 100 & 12 & 0 & 0 & 100 \\
\hline Pan & 5 & 0 & 0 & 100 & 10 & 0 & 0 & 100 \\
\hline Total & 5032 & 0 & $\begin{array}{c}\text { Cumulative } \\
\text { Retained } \\
(\%) \text { Sum }=\end{array}$ & 353 & 5012 & 100 & $\begin{array}{c}\text { Cumulative } \\
\text { Retained } \\
(\%) \text { Sum }=\end{array}$ & 356 \\
\hline
\end{tabular}




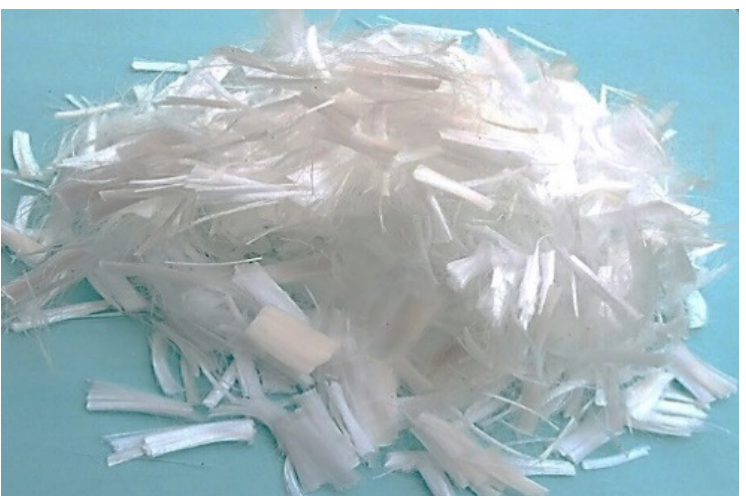

Fig. 6: Polypropylene Fibers

The bonded length was positioned in the middle of the specimen (Fig. 7). The bond free length at both ends was obtained by covering the bar with a thin plastic tube. The ends of plastic tubes were sealed with silicon to avoid the penetration of cement slurry during casting. For the casting of test specimens, concrete was placed in the moulds in three layers. After each layer, moulds were placed on the vibrating table for compaction. A total of 27 pull-out test specimens and 27 cylinders for $\mathrm{f}_{\mathrm{c}}$ ' determination were prepared in this study; three for each concrete composition. After 28 days of casting, pull-out test specimens were tested in a universal testing machine with maximum loading capacity of $1000 \mathrm{kN}$.

To achieve minimum target slump of $75 \mathrm{~mm}$, trial mixes of concrete were prepared. Both NA and RA were used in SSD conditions keeping in mind the high water absorption capacity of RA due to adhered highly porous cement mortar. For all concrete mixes with and without fibers, w/c (Water to Cement Ratio) was 0.55. However, in case of concrete mixes with fibers, a super-plasticizer was used to attain the target slump. The compaction of concrete was done using mechanical vibrating table. The test specimens were demolded after 24 hours and were placed in curing room for 28 days at a temperature of $20^{\circ} \mathrm{C}$ and a relative humidity of $100 \%$.

\section{TESTING PROCEDURES}

\subsection{Compression Test}

The cylindrical specimens were tested under axial compression. Displacement controlled test were performed at loading rate of $2 \mathrm{~mm} / \mathrm{min}$. For each concrete composition, three cylinders were tested and the average value of compressive strength obtained is presented in this contribution.

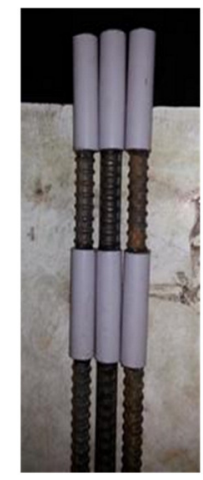

(a) Prepared steel bars

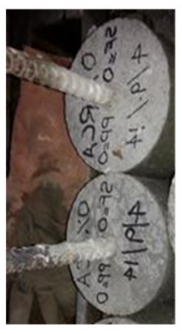

(c) Specimen after de-molding

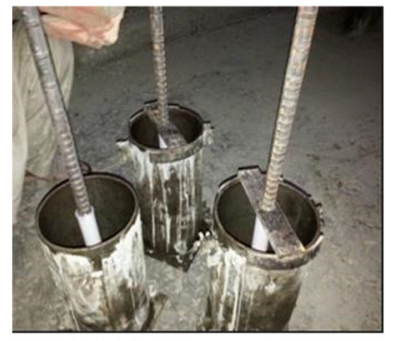

(b) Molds to prepare specimen
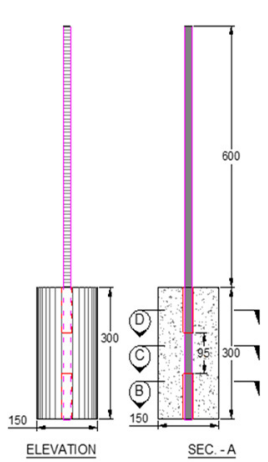

(d) Schematic diagram

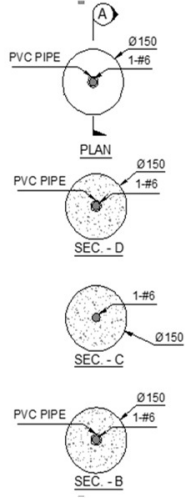

Fig. 7: Pull-Out Test Specimen Detail

\subsection{Pull-out Test}

The testing setup of pull-out test is shown in Fig. 8. The pull-out tests were performed at bar slip rate equal to $2 \mathrm{~mm} / \mathrm{min}$. The pull-out force was measured by load cells placed between machine platen and test specimen as shown in Fig. 8. To measure and record slip in the steel bar, one Linear Variable Displacement Transformer (LVDT) was fixed at the top of steel bar. Both force and bar slip values were recorded automatically by the data acquisition system. Assuming that the bond stresses are uniformly distributed along the bonded length, the bond stress ' $\tau$ ' is calculated by dividing the measured force by the bonded surface area of the deformed steel bar (Equation (1)).

$$
\tau=\frac{\mathrm{F}_{\mathrm{exp}}}{\pi \times \mathrm{d}_{\mathrm{b}} \times \mathrm{L}_{\mathrm{b}}}
$$

where $F_{\text {exp }}$ is Experimental force, $d_{b}$ is Diameter of bar, and $\mathrm{L}_{\mathrm{b}}$ is Embedment length. 


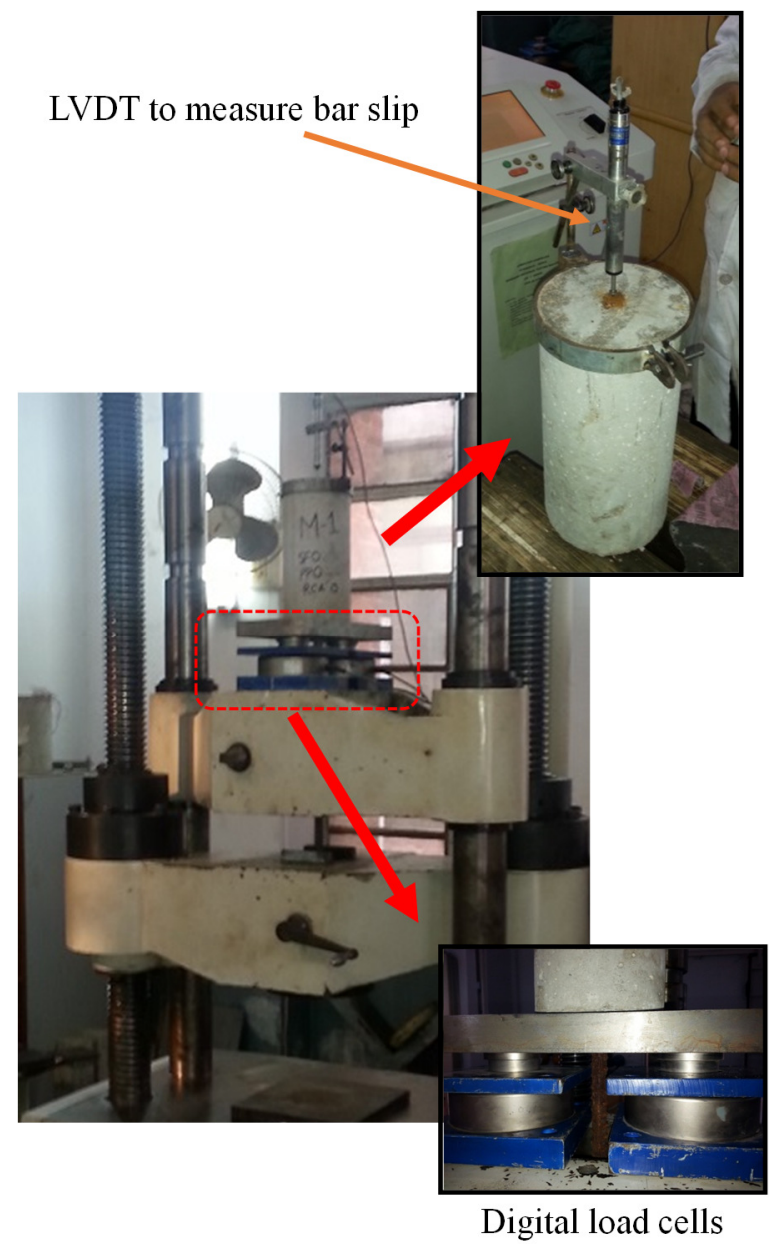

Fig. 8: Testing Arrangement for Pull-Out Test

\section{RESULTS AND DISCUSSION}

The experimental results of compression test and pullout test are presented and discussed in this section. From pull-out test results, peak bond stress and local bond-stress slip behavior of steel reinforcing bars were obtained and the effects of RA and fibers on these properties were explored.

\subsection{Compressive Strength}

Compressive strength values of all concrete mixes are presented in Fig. 9. The results showed that the compressive strength of concrete is decreased as NA are replaced with RA. This observation is in agreement with findings of previous research studies [28-32]. In present case, the compressive strength of concrete mixes RAC50 and RAC100 in Series-I was decreased by 5.7 and $19.0 \%$, respectively when compared to
NAC (Reference Concrete). The drop in compressive strength of RAC was mainly because of the attached mortar/cement paste on the surface of RA (un-treated RA) which resulted in development of weaker Interfacial Transition Zone (ITZ) and consequently, lower compressive strengths. Moreover, during production of RA from $\mathrm{C} \& \mathrm{D}$ waste, cracks development in RA could also be another reason of drop in compressive strength.

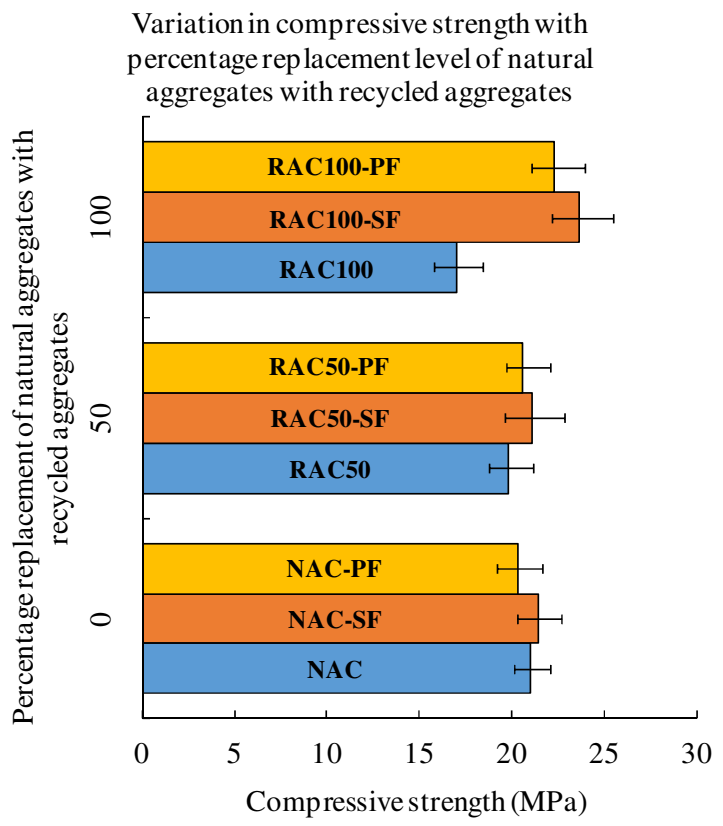

Fig. 9: Compressive Strength Values

Addition of both fibers in mono form in NAC did not affect the compressive strength. However, in case of RAC containing 50\% RA, addition of SF caused slight improvement in compressive strength and RAC50-SF mix exhibited strength value equal to control mix (NAC). On the contrary, addition of PF in RAC50 caused slight improvement in the compressive strength.

It was observed for RAC containing 100\% RA where significant drop in compressive strength was noticed when compared to NAC, that adding both fibers in mono form resulted in not only total recovery of lost strength due to RA but also slight improvement in compressive strength compared to control mix; RAC100-SF \& RAC100-PF mixes exhibited strength value 12 and $6 \%$ higher than NAC, respectively. It is well established fact that fibers come in action of crack 
bridging only when a certain level of damage/cracking is developed within the concrete matrix [8,33-34], therefore, in case of RAC particularly RAC100 mix, required level of internal damage was reached at early stage of loading and fibers came in action earlier in comparison of NAC and restrained the further propagation of the cracks/damage within the matrix up to certain extent. As a consequence, the maximum load carrying capacity of concrete matrix in compression was increased. This showed that by the addition of fibers, it is possible to design RAC mix with $100 \%$ RA exhibiting strength value similar to that NAC.

\subsection{Bond Stress-Slip Response}

The local bond stress slip response of steel re-bar embedded in concrete mixes investigated in this study is presented in Figs. 10-15. In all cases, pull-out failure mode was observed. In order to take into account, the effect of compressive strength, in all presented local bond stress slip response curves, the bond stress is normalized by square root of compressive strength of each concrete type. Fig. 10 clearly indicates that the replacement of NA with RA did not significantly change the overall response of the concrete. The bond stress slip response of RAC50 is almost similar to NAC; however, the overall bond stress slip response is slightly affected negatively when $100 \%$ NA are replaced with RA.

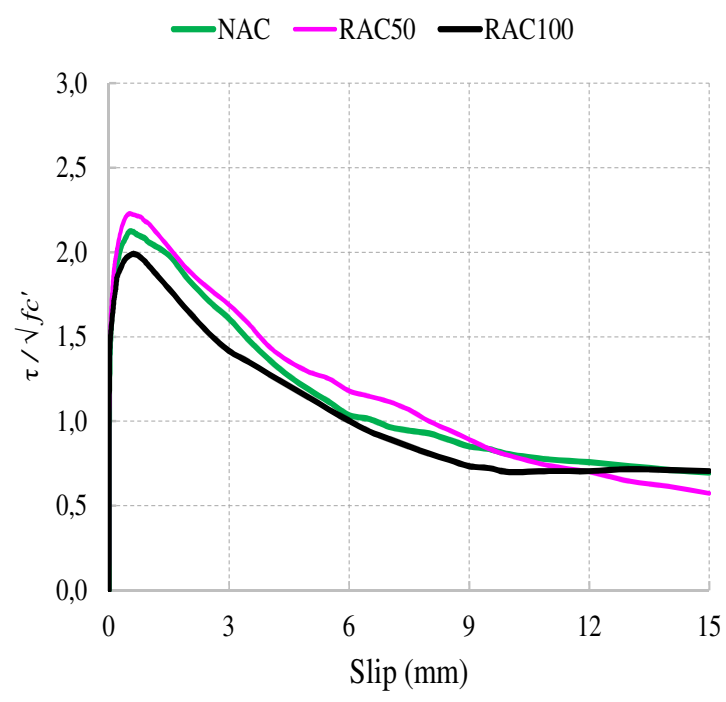

Fig. 10: Bond Stress - Slip Response
The results presented in Fig.11 reveal that with the addition of SF, internal confinement effect is improved and as a result, overall bond stress slip response of both NAC and RACs is improved. In case of RAC50-SF, peak bond stress remains almost the same; however, post peak response is improved when compared to that of NAC and RAC50. The results indicated that the drop in bond stress over wide range of slip value in case of RAC with $100 \%$ RA can be improved with the addition of SF at a dosage of $40 \mathrm{~kg} / \mathrm{m}^{3}$. The results presented in Fig. 12 indicate that addition of PF in NAC improved the overall bond stress slip response, however, addition of PF in RAC50 resulted in significant increase in the peak value but no effect on the post peak response was observed. In opposite to this, addition of $4.4 \mathrm{~kg} / \mathrm{m}^{3}$ of $\mathrm{PF}$ in concrete made using 100\% RA did not affect the peak value but improved the post peak response after $4 \mathrm{~mm}$ slip of steel bars.

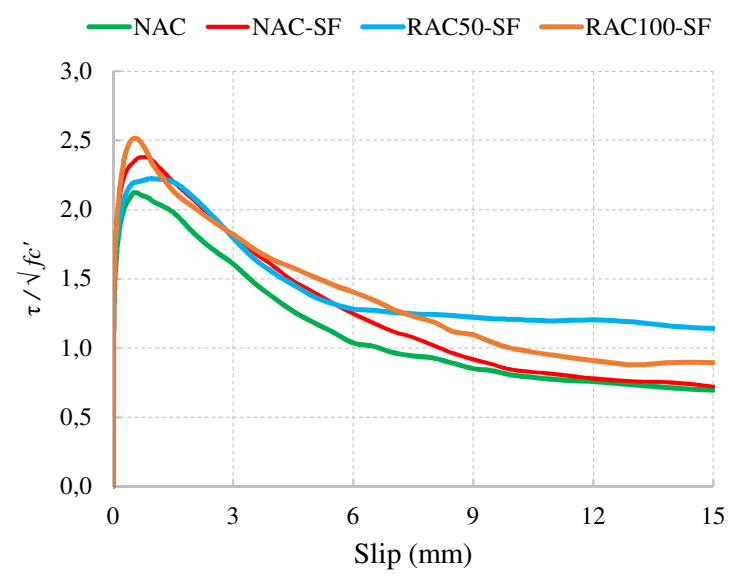

Fig. 11. Bond Stress - Slip Response

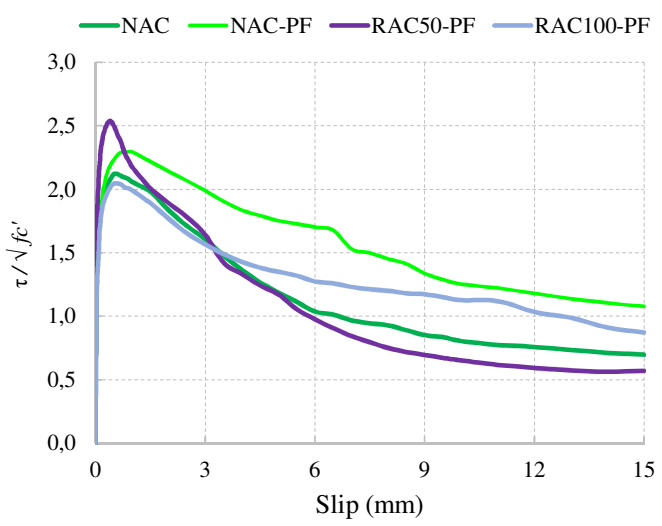

Fig.12: Bond Stress - Slip Response 
In order to compare the effectiveness of SF and PF in improving the bond stress slip response of NAC, response curves of NAC-SF and NAC-PF mixes along with control mix (NAC) are presented in Fig. 13. It is clear in this Fig. 13 that both types of fibers are effective in improving the peak stress compared to NAC; however, PF are more effective as compared to $\mathrm{SF}$ to improve the post peak response. The response curves presented in Fig. 13 revealed that in case of RAC with 50\% RA, addition of SF did not alter the peak stress but slip corresponding to peak stress was slightly increased. On the contrary, addition of PF resulted in appreciable improvement of peak stress.

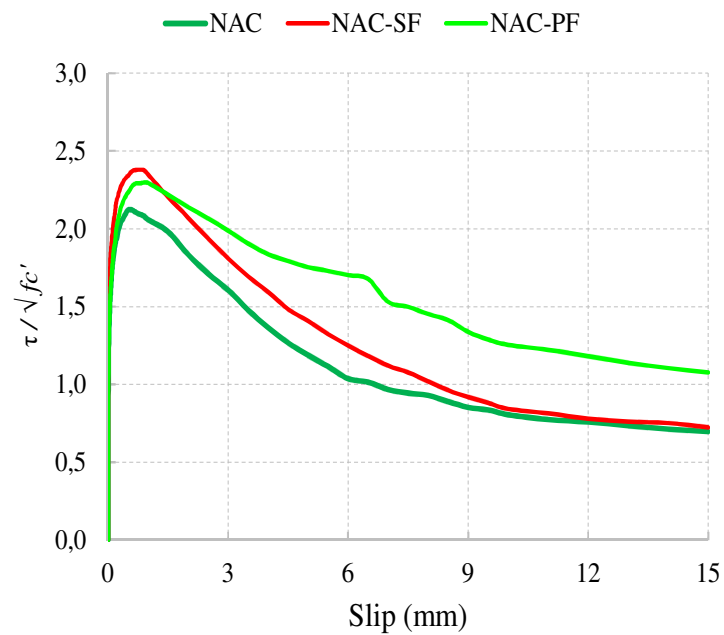

Fig. 13: Bond Stress - Slip Response

In the presence of SF, post peak response of RAC50SF was improved (Fig. 14) and an important value of post peak residual stress value was maintained over a wide range of slip and this bond stress value was greater than the values of RAC50 and RAC50-PF mixes. In opposite to that addition of PF at dosage of $4.4 \mathrm{~kg} / \mathrm{m}^{3}$ negatively affected the post peak response after slip of $3 \mathrm{~mm}$ and with the increase of slip, the residual stress was observed to approach the value of corresponding reference mix of RAC which is RAC50. The response curves of RAC with $100 \%$ RA with and without fibers presented in Fig. 15 show that PF did not affect the peak stress but improved the post peak response when compared to RAC100 mix. Further, in the presence of PF, the drop in residual peak stress was noticed to be decreased with increase of slip. Significant enhancement in peak stress was obtained with the addition of SF in RAC mix with
$100 \%$ RA. In the same mix (RAC100-SF), after the peak, gradual drop in residual stress was noticed with the increase of slip, but the residual stress was greater than the values obtained with RAC100 and RAC100PF (up to 8mm slip).

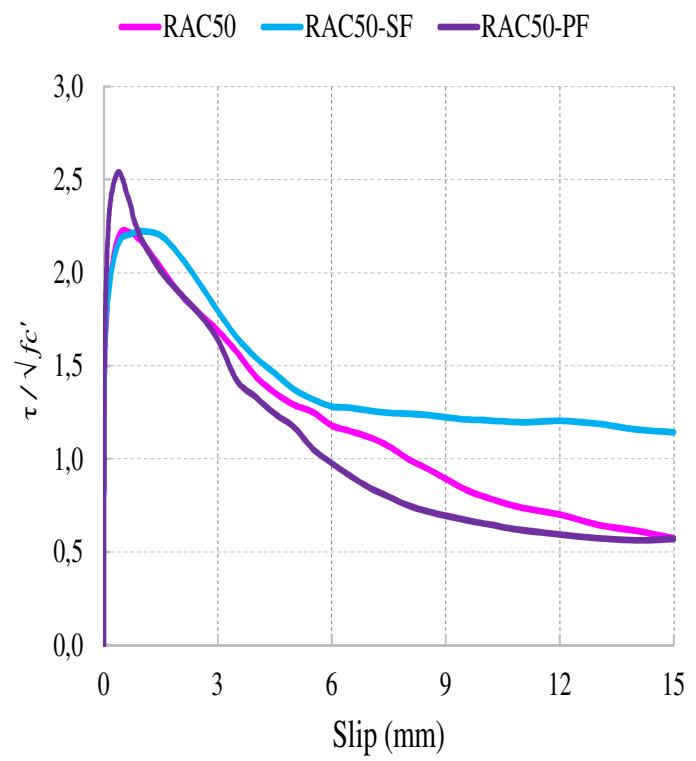

Fig. 14: Bond Stress - Slip Response

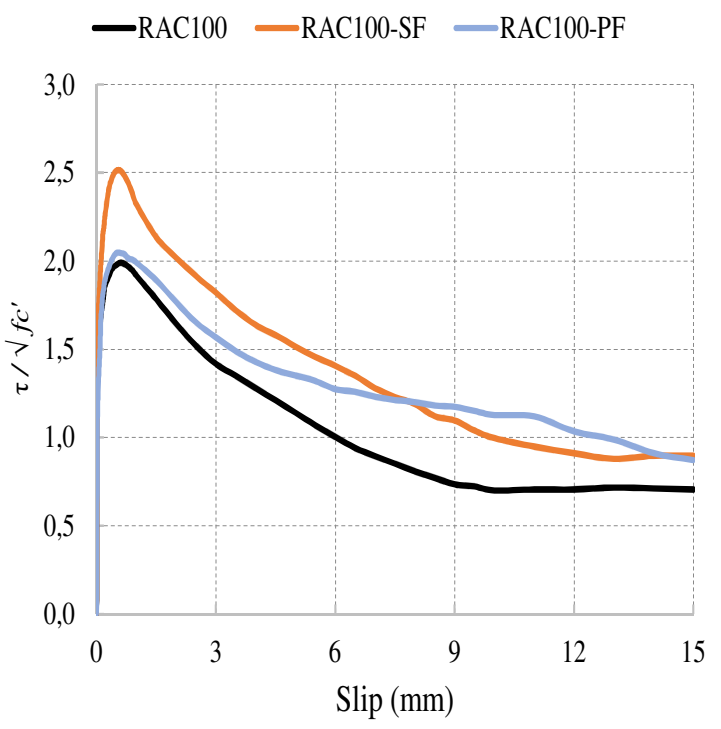

Fig. 15: Bond Stress - Slip Response

\subsection{Bond Strength}

The bond strength was computed using the peak load obtained during pull-out tests. The variation in bond strength of specimens tested in Series-I, Series-II, Series-III with percentage replacement levels of NA with RA is presented in Fig. 16. 


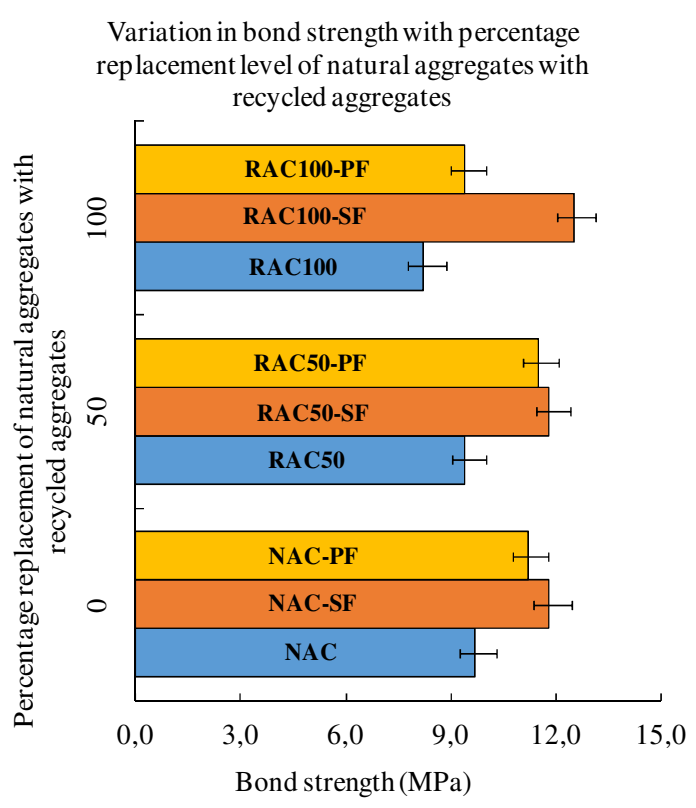

Fig. 16: Bond Strength

Due to replacement of 50 and $100 \%$ NA with RA, the bond strength of embedded steel bar in concrete is decreased by 3 and $15 \%$, respectively. The results revealed that addition of SF improved the bond strength for both NAC and RAC. The maximum improvement was obtained with RAC100-SF. The results further showed that addition of SF not only made it possible to regain the loss in bond strength by replacing NA with RA but also made it possible to get even higher bond strength compared to NAC. Similar to SF, addition of PF also improved the bond strength of NAC and RAC, however, the level of improvement is less as compared to the concrete compositions containing SF. In case of RAC100-SF, increased compressive strength provided more confinement to the steel bar and resulted in higher bond strength. It is obvious in Fig. 16 that RAC50 mix with the addition of both types of fibers in mono form resulted in bond strength even higher than the value obtained with control mix (NAC). However, in case of RAC100 mix, addition of $\mathrm{PF}$ resulted in bond strength 3\% less than the bond strength of NAC, but with the addition of SF, it was possible to get bond strength $28 \%$ greater than the bond strength of NAC.

\subsection{Bond Toughness}

Bond toughness is one of the important properties of reinforced concrete with respect to its application in seismic resistant structures. The bond toughness was computed as area under the load-slip curve up to 15 $\mathrm{mm}$ slip. The values of bond toughness of specimens tested in Series-I, Series-II, Series-III along with percentage replacement levels of NA with RA are presented in Fig. 17.

Variation in bond toughness with percentage replacement level of natural aggregates with recycled aggregates

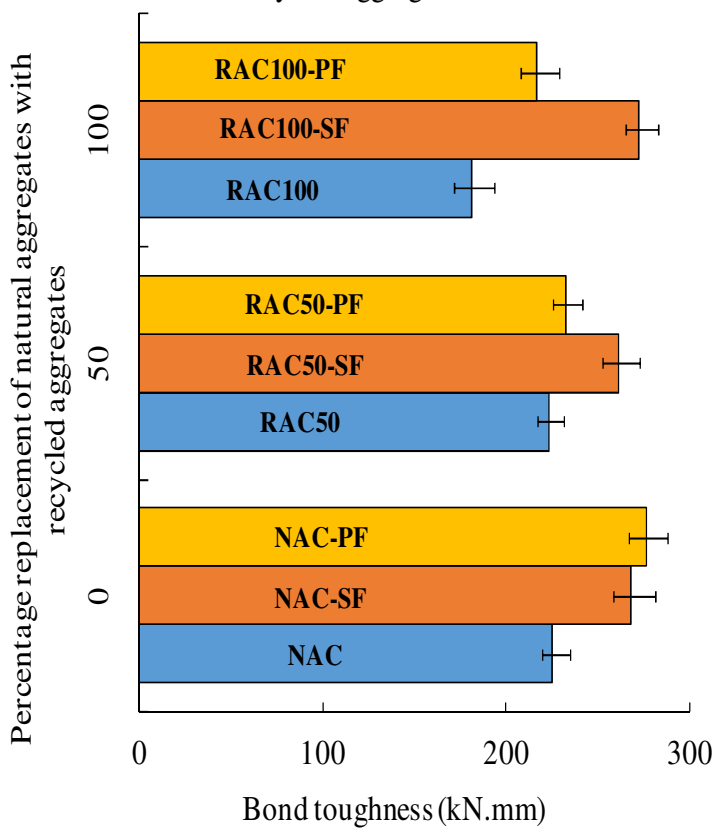

Fig. 17: Bond Toughness

The findings showed that replacement of 50\% NA with RA did not affect the bond toughness and the value remained almost similar to that of NAC. However, $100 \%$ replacement of NA with RA resulted in decrease of bond toughness by $24 \%$ compared to NAC mix. Addition of SF at dosage of $40 \mathrm{~kg} / \mathrm{m}^{3}$ in NAC and RACs enhanced the bond toughness and the maximum enhancement in bond toughness of $50 \%$ was noticed in case of RAC100-SF when compared to RAC100. The improvement in bond toughness in case of NAC-SF and RAC50-SF was almost same when compared to their corresponding concrete mixes without fibers. It is pertinent to mention that significant drop in toughness by the replacement of $100 \%$ NA with RA can be overcome by the addition of SF at a dosage of $40 \mathrm{~kg} / \mathrm{m}^{3}$. The addition of PF also appreciably enhanced the bond toughness of NAC and RAC100 concrete mixes. However, in case of RAC50, 
slight improvement in the value of bond toughness was noticed with the addition of PF.

\section{CONCLUSIONS}

Bond stress slip response of deformed steel bar embedded in NAC and RAC confined by steel and polypropylene fibers was investigated experimentally. The analysis of experimental results made it possible to draw the following conclusions:

(i) Compressive strength of concrete is decreased when NA are replaced with RA. In this study, a drop of 6 and $19 \%$ in compressive strength of NAC was noticed when 50 and $100 \%$ NA were replaced with RA, respectively. However, loss in compressive strength of RAC may be regained by the addition of SF and PF at relatively low dosage which is 40 and $4.4 \mathrm{~kg} / \mathrm{m}^{3}$, respectively. The findings of this study further revealed that addition of SF in RAC mix with $100 \%$ RA not only made it possible to regain the lost strength but also resulted in $17 \%$ enhanced strength when compared to strength value of control mix (NAC). This indicates that it is possible to practically design normal strength RAC mix with $100 \%$ RA with the addition of $40 \mathrm{~kg} / \mathrm{m}^{3}$ of steel fibers.

(ii) General trend of the bond stress slip response curves of deformed steel bar embedded in NAC and RACs was observed to be almost same. Rate of increase and decrease of bond stress up to peak stress and in post peak region, respectively was not significantly affected in the presence of RA.

(iii) Addition of $40 \mathrm{~kg} / \mathrm{m}^{3}$ of SF appreciably improved the overall local bond stress slip response of steel bar embedded in NAC and RACs. Compared to control mix (NAC), maximum increase of $19 \%$ in the peak bond stress value was exhibited by RAC containing $100 \%$ RA. While the increase in peak bond stress by the addition of SF exhibited by NAC and RAC containing 50\% RA was 12 and $5 \%$, respectively compared to control mix (NAC). After the peak, bond stress slip response of deformed steel bar embedded in RAC made using $100 \%$ RA and low dosage of SF (i.e. $40 \mathrm{~kg} / \mathrm{m}^{3}$ ) is found to be even better than the bond stress slip response of steel bar embedded in NAC up to
$15 \mathrm{~mm}$ slip. This indicates that $\mathrm{SF}$ reinforced RAC may be used in RC structural elements.

(iv) The effect of adding $4.4 \mathrm{~kg} / \mathrm{m}^{3}$ of PF in NAC and RACs was different from that of SF. In case of NAC, addition PF significantly improved the overall bond stress slip response of steel bar, but in case of RACs their effect was observed to be dependent on the level of replacement of NA with RA. Improvement in peak bond stress of 20 and $11 \%$ compared to control mix (NAC) and NAC$\mathrm{PF}$, respectively was exhibited by RAC containing 50\% RA (RAC50-PF), however, after $5 \mathrm{~mm}$ slip, the residual bond stress was less than that of control mix. On the contrary, bond stress slip response of steel bar embedded in RAC containing $100 \%$ RA was almost similar to that of control mix up to $3 \mathrm{~mm}$ slip and after this stage residual bond stress value is increased significantly compared to control mix but remains less than the value exhibited by NAC-PF.

(v) For improvement in peak bond stress of RAC made using $50 \%$ RA, PF are better option, however, SF are more effective in improving the residual bond stress of the same concrete mix. Based on this observation, for RAC mix containing 50\% RA, use of SF and PF in hybrid form would be a better option which will result in the overall improvement in the bond stress slip response.

(vi) Bond toughness remains unaffected up to $50 \%$ replacement of NA with RA. However, a decrease of $24 \%$ was observed for RAC containing $100 \%$ RA (RAC100). Results show that this loss in bond toughness due to $100 \%$ replacement of NA with RA may be regained by the addition of SF and PF at dosages of 40 and $4.4 \mathrm{~kg} / \mathrm{m}^{3}$, respectively. Further, the effect of addition of steel fibers on the regain of lost bond toughness is $25.8 \%$ more than that of PF in case of RAC containing $100 \%$ RA (RAC100). These findings indicate that RAC with $100 \% \mathrm{RA}$ and $40 \mathrm{~kg} / \mathrm{m}^{3}$ of steel fibers may be used for concrete construction in earthquake prone regions.

\section{ACKNOWLEDGEMENT}

Technical and financial support from Imporient Chemicals (Pvt.), Lahore, Pakistan, for this research 
work is highly acknowledged.

\section{REFERENCES}

[1]. Xiao, J., Li, W., Fan, Y., and Huang, X., “An overview of study on recycled aggregate concrete in China (1996-2011)", Construction and Building Materials, Vol. 31, pp. 364-383, 2012.

[2]. ACI 555 R-01, "Removal and Reuse of Hardened Concrete", American Concrete Institute, 2001.

[3]. Matias, D., de Brito, J., Rosa, A., and Pedro, D., "Mechanical properties of concrete produced with recycled coarse aggregates - Influence of the use of super-plasticizers", Construction and Building Materials, Vol. 44, pp. 101-109, 2013.

[4]. Padmini, A.,K., Ramamurthy, K., and Mathews, M.,S., "Influence of parent concrete on the properties of recycled aggregate concrete", Construction and Building Materials, Vol. 23, pp. 829-836, 2009.

[5]. Xiao, J., Li, J., and Zhang, C., "Mechanical properties of recycled aggregate concrete under uniaxial loading, Cement and Concrete Research, Vol. 35, pp.1187-1194, 2005.

[6]. Banthia, N., and Sappakittipakorn, M., "Toughness enhancement in steel fiber reinforced concrete through fiber hybridization", Cement and Concrete Research, Vol. 37, pp.1366-1372, 2007.

[7]. Hameed, R., Turatsinze, A., Duprat, F., and Sellier, A., "Metallic fiber reinforced concrete: Effect of fiber aspect ratio on the flexural properties", ARPN Journal of Engineering and Applied Sciences, Vol. 4, pp.67-72, 2009.

[8]. Hameed, R., Turatsinze, A., Duprat, F., and Sellier, A., "Study on the flexural properties of metallic-hybrid-fibre-reinforced concrete", Maejo International Journal of Science and Technology, Vol. 4, pp.169-184, 2010.

[9]. Hameed, R., Turatsinze, A., Duprat, F., and Sellier, A., "A study on the reinforced fibrous concrete elements subjected to uniaxial tensile loading", KSCE Journal of Civil Engineering, Vol. 14: pp.547-556, 2010.

[10]. Gao, D., Zhanga, L., and Nokkenc, M., "Mechanical behavior of recycled coarse aggregate concrete reinforced with steel fibers under direct shear", Cement and Concrete Composites, Vol. 79, pp. 1-8, 2017.

[11]. Carneiro, J., A., Lima, P., R., L., Leite, M., B., and Filho, R., D., T., "Compressive stressstrain behavior of steel fiber reinforced-recycled aggregate concrete", Cement and Concrete Composites, Vol. 46, pp. 65-72, 2014.

[12]. Sryh, L., and Forth, J., "Experimental investigation on the effect of steel fibres on the mechanical properties of recycled aggregate concrete", Fibre Concrete 2015, September 1011, Prague, Czech Republic, 2015.

[13]. Mohsen, A., Saeed, F., Abolfazl H., and Mana M., "Mechanical properties of the concrete containing recycled fibers and aggregates", Construction and Building Materials, Vol. 144, pp. 392-398, 2017.

[14]. Danying, G., Lijuan, Z., and Michelle, N., "Mechanical behavior of recycled coarse aggregate concrete reinforced with steel fibers under direct shear", Cement and Concrete Composites, Vol. 79, pp. 1-8, 2017.

[15]. Chandra, S., D., Tanish D., Ramkrishna D., Bibhuti B., M., and Jitendra K., "Performance evaluation of polypropylene fibre reinforced recycled aggregate concrete", Construction and Building Materials, Vol. 189, pp. 649-659, 2018.

[16]. Kazmi, S., M., S., Munir, M., J., Zu, Y-F., and Patnaikuni, I., "Effect of macro-synthetic fibers on the fracture energy and mechanical behavior of recycled aggregate concrete", Construction and Building Materials, Vol. 189, pp. 857-868, 2018.

[17]. Kazmi, S., M., S., Munir, M., J., Zu, Y-F., Patnaikuni, I., Zhou, Y., and Xing, F., "Axial stress-strain behavior of macro-synthetic fiber reinforced recycled aggregate concrete", Cement and Concrete Composites, Vol. 97, pp. 341-356, 2019.

[18]. Sajid, M., and Faheem, B., "Effect of Steel Fibers on Heat of Hydration and Mechanical Properties of Concrete Containing Fly Ash", Mehran University Research Journal of Engineering and Technology, Vol. 38, No. 1, pp. 83-94, 2019.

[19]. Xiao, J., and Falkner, H., "Bond behaviour 
between recycled aggregate concrete and steel rebars", Construction and Building Materials, Vol. 21, pp. 395-401. 2007.

[20]. Prince, M., J., R., and Singh, B., "Bond behaviour of deformed steel bars embedded in recycled aggregate concrete", Construction and Building Materials, Vol. 49, pp. 852-862, 2013.

[21]. Kim, S-W., Yun, H-D., Park, W-S., and Jang, Y., "Bond strength prediction for deformed steel rebar embedded in recycled coarse aggregate concrete", Materials and Design, pp. 83: 257269, 2015.

[22]. Xiao, J., and Falkner, H., "Bond behaviour between recycled aggregate concrete and steel rebars", Construction and Building Materials, Vol. 21, pp. 395-401, 2007.

[23]. Hamad, B., S., Harajli, M., H., and Jumaa, G., "Effect of Fiber Reinforcement on Bond Strength of Tension Lap Splices in HighStrength Concrete", ACI Structural Journal, Vol. 98, pp. 638-647, 2001.

[24]. Harajli, M., H., and Mabsout, M., E., "Evaluation of Bond Strength of Steel Reinforcing Bars in Plain and Fiber-Reinforced Concrete", ACI Structural Journal, Vol. 99, No. 4, pp. 509-517, 2002.

[25]. Bilal, S., H., Elias, Y., A., H., Harajli, M., H., "Effect of Steel Fibers on Bond Strength of Hooked Bars in Normal-Strength Concrete", ACI Structural Journal, Vol. 108, No. 1, pp.4250, 2011.

[26]. Hameed, R., Turatsinze, A., Duprat, F., and Sellier, A., "Bond stress-slip behavior of steel reinforcing bar embedded in hybrid fiberreinforced concrete", KSCE Journal of Civil Engineering, Vol. 17, No.7, pp. 1700-1707, 2013.

[27]. Choi, K., "Anchorage of beam reinforced at conventional and fibrous beam-column connections", PhD Thesis, Michigan State University, USA, 1998.

[28]. Bravo, M., Brito, J., Pontes, J., and Evangelista, L., "Mechanical performance of concrete made with aggregates from construction and demolition waste recycling plants", Journal of Cleaner Production, Vol. 99, pp. 59-74, 2015.

[29]. Riaz, M., R., Hameed, R., Ilyas, M., Akram, A., and Siddiqi, Z., A., "Mechanical Characterization of Recycled Aggregate Concrete", Pakistan Journal of Engineering and Applied Sciences, Vol. 16, pp. 25-32, 2015.

[30]. McGinnis, M., J., Davis, M., de la Rosa, A., Weldon, B., D., and Kurama, Y., C., "Strength and stiffness of concrete with recycled concrete aggregates", Construction and Building Materials, Vol. 154, pp. 258-269, 2017.

[31]. Lau, T., L., Elleithy, W., Choong, W., K., Tze, T., Y., Lee, C., M., Modhwadia, A., L., "Effects of recycled aggregates on concrete strengths", Materials Research Innovations, Vol. 18, pp. 372-374, 2014.

[32]. Abdulla, N., A., "Effect of recycled coarse aggregate type on concrete", Journal of Materials in Civil Engineering, Vol. 27, No. 10, pp.1-9, 2015.

[33]. Pons, G., Mouret, M., Alcantrara, M., and Granju, J., L., "Mechanical behaviour of selfcompacting concrete with hybrid fiber reinforcement", Material and Structures, Vol. 40, pp. 201-210, 2007.

[34]. Kim, D.J., Naaman, A., E., and El-Tawil, S., "Comparative flexural behaviour of four fiber reinforced cementitious composites", Cement and Concrete Composites, Vol. 30, pp. 917-928, 2008. 